\title{
Changing incidence of peptic ulcer-facts or artefacts? A cohort study from Tromsø
}

\author{
Roar Johnsen, Bjørn Straume, Olav Helge Førde, Per G Burhol
}

\begin{abstract}
Study objective-The aim was to estimate the age and sex specific incidences of duodenal and gastric ulcers censored for death and migration.

Design-A population based cohort was followed seven years through records of $x$ ray examinations, endoscopies, and operations in the only hospital serving the area.

Setting-The study was conducted in the municipality of Tromse, Northern Norway, where all men aged 20 to 54 years and women aged 20 to 49 years in 1980, a total of 21 440, were included.

Main results-We found an incidence of $1.47(95 \%$ CI 1.21-1.76) and 0.88 (0.67-1.14) per 1000 person-years for gastric and 1.98 $(1.69-2 \cdot 31)$ and $0.85(0.64-1 \cdot 11)$ for duodenal ulcers in men and women, respectively. A small and insignificant sex difference for gastric ulcer was noted. The duodenal preponderance in men was only recognised among the ulcers identified by $x$ ray, not among ulcers diagnosed by endoscopy.

Conclusions-This population based study has, in contrast to recent studies from other areas, revealed an unchanged high incidence of gastric and duodenal ulcer in both sexes. Compared to earlier studies from this area it indicates a preponderance of duodenal ulcers. The study also shows the impact of attendance rate, death, and migration, and of diagnostic methods on the incidence estimates. Ignoring these potential biases may lead to conclusions on peptic ulcer trends that reflect artefacts rather than real changes in peptic ulcer occurrence.
\end{abstract}

f Epidemiol Community Health 1992; 46: 433-436

Institute of Community Medicine, Postuttak, N-9001 Tromse, Norway R Johnsen B Straume O H Forde Laboratory of Gastroenterology, Department of Medicine, University
Mepartment of Mospital of Tromse, Tromse, Norway P G Burhol

Correspondence to: Dr Johnsen

Accepted for publication October 1991 dence of peptic ulcer in some western countries is mainly based on mortality rates, ${ }^{1-35-8}$ perforation rates, ${ }^{5-79}$ and hospital admissions and physician visit rates. ${ }^{56-11}$ Besides reflecting changes in peptic ulcer occurrence, these findings may mirror changes in clinical and coding practice as well. ${ }^{6}$ The few published prospective studies are neither consistent regarding a declining incidence, ${ }^{12-17}$ nor are they directly comparable due to disparities in design, diagnostic techniques, and definitions of peptic ulcer. Apparently in contrast to findings from all other western societies, a duodenal to gastric ulcer ratio of one or less has been observed in several studies 151819 from northern Norway.

Both the identification of population at risk and the verification of diseased subjects appear to be major methodological problems in most incidence studies, and Sturdevant ${ }^{20}$ has requested future studies to secure "a precise ascertainment of affected individuals, and precise definitions of population under study".

A comprehensive health survey of 21440 inhabitants of the municipality of Tromsø gave us the opportunity to study the incidence of diagnosed peptic ulcers, in a defined population, censored for death and migration.

\section{Methods}

In a health survey in the municipality of Tromsø in 1979-80, all men born between 1925 and 1959, and all women born between 1930 and 1959 were invited to participate, a total of 21440 . At the screening 16621 attended, of whom 14667 returned a supplementary questionnaire on several items concerning health and lifestyle. ${ }^{21}$

The University Hospital in Tromsø serves as the only hospital in the area, and all first occurring peptic ulcers diagnosed by $x$ ray examination, upper gastrointestinal endoscopy, or operation in the study population were registered during the period 1979 and 1987. To ensure that all registered ulcers were "new" or incident, the medical records of all cases were examined.

The double contrast method of $x$ ray examinations has been the standard in the department of radiology since $1976 .{ }^{15} \mathrm{~A}$ gastric or a duodenal ulcer was diagnosed if a radiological niche was demonstrated $3 \mathrm{~cm}$ proximal or distal to the pylorus, respectively; or if an endoscopic ulceration of at least $0.5 \mathrm{~cm}$ was seen proximal or distal to the pylorus, respectively. Only one ulcer episode was recorded in each subject, except for combined ulcers, diagnosed at different points in time. Thus when the total number of peptic ulcers is given this corresponds to the number of subjects with new peptic ulcers. 
The population at risk was censored for all deaths, recorded by the Central Bureau of Statistics of Norway during the period (237 men and 67 women). We got information from the Bureau on individual migration in the study population (2234 men and 2099 women), but no the exact date of their migration. As an approximation for censoring purposes all migrations were recorded as having occurred in the middle of the follow up period, ie, we used 3.5 years as the mean observation time for these persons.

\section{STATISTICS}

Incidence rates were estimated as numbers of first time peptic ulcers per 1000 person-years, censored for the time of diagnoses of petic ulcers, for deaths during the period, and for migration. ${ }^{22}$ The relationship between age, sex, and incidence of peptic ulcers was tested by Cochran-MantelHaenszel statistics. ${ }^{22}$ Confidence intervals were calculated from the binomial distribution.

\section{Results}

Of the 21440 subjects invited to the screening, 328 experienced their first peptic ulcer episode during follow up, and the majority were diagnosed by $x$ ray. Table I illustrates that the pattern of peptic ulcer location depended on whether diagnoses where made by endoscopy or $x$ ray. Exploring whether the difference could be explained by patient selection failed to reveal significant differences according to age, sex, or the relevant symptoms recorded in 1979/80. Excluding combined ulcers and deformities of the bulb, there were still more duodenal ulcers diagnosed by $x$ ray. During the observation period, 83 persons had surgery because of their ulcer disease: 49 persons were operated electively while 34 had emergency surgery because of bleeding or perfor-

Table I Number of subjects with peptic ulcers by ulcer location and methods of diagnosis. Tromso 1980-87

\begin{tabular}{llllll}
\hline & $\begin{array}{l}\text { Gastric } \\
\text { ulcer }\end{array}$ & $\begin{array}{l}\text { Duodenal } \\
\text { ulcer }\end{array}$ & $\begin{array}{l}\text { Combined } \\
\text { ulcer }\end{array}$ & $\begin{array}{l}\text { Deformity } \\
\text { of the bulb }\end{array}$ & Total \\
\hline Endoscopy & 65 & 52 & 21 & 1 & 139 \\
$X$ ray & 59 & 83 & 9 & 27 & 178 \\
Operation & 7 & 4 & - & - & 11 \\
\hline
\end{tabular}

${ }^{\mathrm{a}}$ Ulcers diagnosed both by $x$ ray and endoscopy are grouped under endoscopy ation. Of these 34 persons only 11 had "new" or incident ulcers.

A separate analysis showed a somewhat higher incidence of total peptic ulcer among responders compared to non-responders, though statistically non-significant. However, the incidence among the youngest male responders, aged 20 to 34 years, of 2.17 per 1000 person-years $(95 \%$ CI: 1.74 2.79) was twice that of the non-responders, 1.08 (0.57-1.84).

The age and sex specific incidences of gastric, duodenal and total ulcers, respectively, are shown in table II. Excluding from the analysis 532 subjects who reported having had a peptic ulcer before $1979 / 80$ gave an overall peptic ulcer incidence per 1000 person-year of 3.29 among men and 1.63 in women, compared to 3.18 and 1.61 as shown in table II. Duodenal ulcers included 28 first diagnoses of deformity of the duodenal bulb in 21 men and seven women. Twenty two men and eight women had combined ulcers.

A significant linear trend with increasing age was found, both for gastric $(p<0.001)$ and duodenal ulcer $(p<0.001)$. A duodenal predominance was found among young females, and, most pronounced, in middle aged males. Overall, the ratios between duodenal and gastric ulcers were $1.4(1.0-1.8)$ and $1.0(0.6-1.4)$ for men and women, respectively. Among the youngest females, aged 20 to 29 years, the ratio was $2 \cdot 2$ $(0 \cdot 7-7 \cdot 2)$.

The effect of censoring for death and migration is illustrated by contrasting table III with table II. The censored incidences of peptic ulcer were $13 \%$ higher than the uncensored in both sexes. The consequence (an underestimate) of not censoring was greatest among the youngest urbans, with approximately a $20 \%$ difference between uncensored and censored incidences.

\section{Discussion}

The changing pattern in incidence of peptic ulcer disease in different age and sex cohorts has been ascribed to the adoption of industrialised civilisation. ${ }^{2}$ However, to some degree new diagnostic technology, change in treatment from surgical to medical therapy, ${ }^{23}$ and a shift in coding practice ${ }^{6}$ may also have influenced the perceived trends in peptic ulcer epidemiology. In addition expensive

Table II The incidences (per 1000 person-years) of new peptic ulcers by age, censored for death and migration, among 11483 men and 9957 women. Tromso $1980-87.95 \%$ Confidence intervals in brackets

\begin{tabular}{|c|c|c|c|c|c|c|c|c|c|c|c|c|c|c|}
\hline \multirow{3}{*}{$\begin{array}{l}\text { Age } \\
\text { (years) }\end{array}$} & \multicolumn{2}{|c|}{ Person-years } & \multicolumn{4}{|c|}{ Gastric ulcer ${ }^{\mathbf{a}}$} & \multicolumn{4}{|c|}{ Duodenal ulcer ${ }^{\text {b }}$} & \multicolumn{4}{|c|}{ Total ulcers } \\
\hline & \multirow[t]{2}{*}{ Men } & \multirow[t]{2}{*}{ Women } & \multicolumn{2}{|l|}{ Men } & \multicolumn{2}{|c|}{ Women } & \multicolumn{2}{|l|}{ Men } & \multicolumn{2}{|c|}{ Women } & \multicolumn{2}{|l|}{ Men } & \multicolumn{2}{|c|}{ Women } \\
\hline & & & $n$ & Incidence & $n$ & Incidence & $n$ & Incidence & $n$ & Incidence & $n$ & Incidence & $n$ & Incidence \\
\hline $20-24$ & 10847 & 11597 & 7 & $\begin{array}{l}0.65 \\
(0 \cdot 26-1 \cdot 33)\end{array}$ & 2 & $\begin{array}{c}0.17 \\
(0.02-0.62)\end{array}$ & 9 & $\begin{array}{c}0.83 \\
(0.38-1.58)\end{array}$ & 4 & $\begin{array}{c}0.34 \\
(0.09-0.88)\end{array}$ & 14 & $\begin{array}{c}1 \cdot 29 \\
(0 \cdot 71-2 \cdot 16)\end{array}$ & 6 & $\begin{array}{c}0.52 \\
(0 \cdot 19-1 \cdot 13)\end{array}$ \\
\hline $25-29$ & 13468 & 13603 & 12 & $\begin{array}{l}0.89 \\
(0.46-1.55)\end{array}$ & 3 & $\begin{array}{c}0.22 \\
(0.04-0.64)\end{array}$ & 16 & $\begin{array}{c}1 \cdot 19 \\
(0 \cdot 68-1.90)\end{array}$ & 7 & $\begin{array}{l}0.51 \\
(0.21-1.06)\end{array}$ & 26 & $\begin{array}{c}1.93 \\
(1.26-2.41)\end{array}$ & 9 & $\begin{array}{l}0.66 \\
(0.30-1.26)\end{array}$ \\
\hline $30-34$ & 14017 & 13322 & 12 & $\begin{array}{l}0.86 \\
(0.44-1.49)\end{array}$ & 11 & $\begin{array}{c}0.83 \\
(0.41-1.48)\end{array}$ & 22 & $\begin{array}{l}1.57 \\
(1.04-2.64)\end{array}$ & 8 & $\begin{array}{l}0.60 \\
(0 \cdot 26-1 \cdot 19)\end{array}$ & 31 & $\begin{array}{l}2 \cdot 21 \\
(1 \cdot 51-3 \cdot 12)\end{array}$ & 18 & $\begin{array}{l}1.35 \\
(0 \cdot 80-2 \cdot 13)\end{array}$ \\
\hline $35-39$ & 11369 & 10127 & 12 & $\begin{array}{l}1.06 \\
(0 \cdot 79-2 \cdot 68)\end{array}$ & 11 & $\begin{array}{l}1.09 \\
(0.54-1.95)\end{array}$ & 31 & $\begin{array}{l}2.73 \\
(2.09-4.33)\end{array}$ & 11 & $\begin{array}{l}1.09 \\
(0.54-1.95)\end{array}$ & 40 & $\begin{array}{c}3.52 \\
(2.52-4.76)\end{array}$ & 21 & $\begin{array}{l}2 \cdot 07 \\
(1 \cdot 28-3 \cdot 16)\end{array}$ \\
\hline $40-44$ & 7809 & 7201 & 13 & $\begin{array}{l}1.66 \\
(0.88-2.84)\end{array}$ & 12 & $\begin{array}{c}1.67 \\
(0.86-2.90)\end{array}$ & 23 & $\begin{array}{l}2.95 \\
(1.87-4.41)\end{array}$ & 16 & $\begin{array}{c}2.22 \\
(1 \cdot 28-3 \cdot 60)\end{array}$ & 33 & $\begin{array}{c}4 \cdot 23 \\
(2 \cdot 92-5 \cdot 90)\end{array}$ & 26 & $\begin{array}{l}3 \cdot 61 \\
(2 \cdot 36-5 \cdot 26)\end{array}$ \\
\hline $45-49$ & 7086 & 6352 & 28 & $\begin{array}{c}3.95 \\
(2 \cdot 64-5 \cdot 69)\end{array}$ & 16 & $\begin{array}{l}2.52 \\
(1.85-4.08)\end{array}$ & 20 & $\begin{array}{l}2.82 \\
(1.72-4.35)\end{array}$ & 7 & $\begin{array}{l}1 \cdot 10 \\
(0 \cdot 44-2 \cdot 27)\end{array}$ & 43 & $\begin{array}{l}6 \cdot 07 \\
(4 \cdot 42-8 \cdot 11)\end{array}$ & 20 & $\begin{array}{l}3.15 \\
(1.92-4.85)\end{array}$ \\
\hline $50-54$ & 6987 & - & 21 & $\begin{array}{l}3.01 \\
(1.86-4.58)\end{array}$ & - & & 24 & $\begin{array}{c}3 \cdot 43 \\
(2 \cdot 20-5 \cdot 08)\end{array}$ & - & & 41 & $\begin{array}{l}5 \cdot 87 \\
(4 \cdot 24-7.91)\end{array}$ & - & \\
\hline Total & 71589 & 62202 & 105 & $\begin{array}{l}1 \cdot 47 \\
(1 \cdot 21-1 \cdot 76)\end{array}$ & - & & 142 & $\begin{array}{l}1.98 \\
(1 \cdot 69-2 \cdot 31)\end{array}$ & - & & 228 & $\begin{array}{l}3 \cdot 18 \\
(2 \cdot 83-3 \cdot 57)\end{array}$ & - & \\
\hline \multicolumn{3}{|c|}{ Total (20-49) } & 84 & $\begin{array}{l}1.30 \\
(1.05-1.59)\end{array}$ & 55 & $\begin{array}{l}0 \cdot 88 \\
(0 \cdot 67-1 \cdot 14)\end{array}$ & 118 & $\begin{array}{c}1.83 \\
(1.53-2 \cdot 16)\end{array}$ & 53 & $\begin{array}{l}0.85 \\
(0.64-1 \cdot 11) \\
\end{array}$ & 187 & $\begin{array}{l}2.89 \\
(2.53-3.29)\end{array}$ & 100 & $\begin{array}{c}1.61 \\
(1.32-1.93)\end{array}$ \\
\hline
\end{tabular}


new drugs are refunded in many countries, Norway included, only if a peptic ulcer is documented by $x$ ray or endoscopy. This presumably increases the referral rates among dyspeptics, and thereby the possibility of detecting an ulcer. Still, the occurrence of silent and undiagnosed peptic ulcer is surprisingly high, indicating that peptic ulcer disease is considerably more frequent than is clinically recognised. ${ }^{24}$ Furthermore, a variety of selection mechanisms hampers comparisons of ulcer incidences based on admission rates, necropsy studies, and prospective studies on differing patient groups, with considerable bias. Even perforation rates and mortality rates are unreliable as estimates of peptic ulcer incidences, reflecting differences in rates of complications rather than true differences in peptic ulcer occurrence.

This study was population based, with explicitly defined end points including ulcers diagnosed by $x$ ray, endoscopy, and at operation. It was also an unbiased assessment of the population at risk, which implies controlling for sex and age distribution, and censoring for death and migration.

The reported decline in hospital admissions, 5910 perforation, and mortality rates ${ }^{578}$ is somewhat inconsistent regarding its relation to age and sex. Besides, in the United Kingdom the decrease in peptic ulcer is mainly accounted for by gastric ulcer, while the decline in the USA affects the duodenal location. Kurata claims that the decline in the USA can partly be ascribed to changes in coding practices, hospital admission criteria, and diagnostic procedures. ${ }^{6}$ However, perforation rates and cause specific mortality of peptic ulcer, as opposed to diagnosis, are hard end points, and the evidence of a shift in the presentation and complication rates of peptic ulcer seems difficult to disregard.

Incidence studies published in the United Kingdom, ${ }^{13} 14$ the USA, ${ }^{12}$ and Scandinavia, ${ }^{15-17}$ are not conclusive in showing a decline in the occurrence of peptic ulcer. The Scandinavian studies of Østensen et al ${ }^{15}$ and Bonnevie, ${ }^{1617}$ in particular, give no indication of a declining incidence. However, the studies are not comparable, due to differences in the selection of the populations at risk, diagnostic criteria, and diagnostic methods applied. Our study shows that the pattern of ulcer location depends on the method of the diagnostic examination. Both $x$ ray examination and endoscopy are, according to Dooley et $a l,{ }^{25}$ specific, but the low sensitivity inherent in $x$ ray examinations may result in numerous false

Table III The uncensored incidences (per 1000 person-years) of new peptic ulcers by age in 11483 men and 9957 women. Tromse 1987

\begin{tabular}{|c|c|c|c|c|c|c|}
\hline \multirow[b]{3}{*}{ Age (years) } & \multicolumn{3}{|l|}{ Men } & \multicolumn{3}{|l|}{ Women } \\
\hline & \multirow[t]{2}{*}{ Person-years } & \multicolumn{2}{|c|}{ Peptic ulcer } & \multirow[t]{2}{*}{ Person-years } & \multicolumn{2}{|c|}{ Peptic ulcer } \\
\hline & & $n$ & Incidence & & $n$ & Incidence \\
\hline $\begin{array}{l}20-24 \\
25-29 \\
30-34 \\
35-39 \\
40-44 \\
45-49 \\
50-54\end{array}$ & $\begin{array}{r}12522 \\
15864 \\
16042 \\
12486 \\
8461 \\
7517 \\
7518\end{array}$ & $\begin{array}{l}14 \\
26 \\
31 \\
40 \\
33 \\
43 \\
41\end{array}$ & $\begin{array}{l}1.12 \\
1.64 \\
1.93 \\
3.20 \\
3.90 \\
5.72 \\
5.45\end{array}$ & $\begin{array}{r}14099 \\
16167 \\
14809 \\
10866 \\
7635 \\
-\quad 6689\end{array}$ & $\begin{array}{r}6 \\
9 \\
18 \\
21 \\
26 \\
20 \\
-\quad\end{array}$ & $\begin{array}{l}0.43 \\
0.56 \\
1.22 \\
1.93 \\
3.41 \\
2.99 \\
-\end{array}$ \\
\hline Total & 80416 & 228 & $\begin{array}{l}2 \cdot 87^{\mathrm{a}} \\
(2 \cdot 52-3 \cdot 17)^{\mathrm{b}}\end{array}$ & 70263 & 100 & $\begin{array}{l}1.47^{\mathrm{a}} \\
(1 \cdot 17-1 \cdot 71)^{\mathrm{b}}\end{array}$ \\
\hline
\end{tabular}

a Age adjusted by direct standardisation
${ }^{65 \%} \%$ confidence interval negative findings. The uncertainties caused by these methodological problems make it difficult to be confident that there is a declining incidence of peptic ulcer. Schache $e t$ al even claim that there has been no change in the incidence of duodenal ulcer, but only in the pattern of presentation. ${ }^{26}$

The high incidences in our study may reflect an increasing diagnostic intensity, due to refunding of the cost of drugs prescribed for ulcers, as well as to more efficient diagnostic investigations. The number of examinations has, however, been constant during the follow up period with a declining use of $x$ ray examinations with a corresponding increase in endoscopies. The frequency of positive findings varied throughout the period, with no significant trend.

Contrary to the duodenal ulcer predominance found in Denmark, ${ }^{16} 17$ the USA, ${ }^{12}$ and the United Kingdom ${ }^{13} 14$ a gastric ulcer predominance has been observed in northern Norway. ${ }^{15} 1819$ Our findings of a predominance of duodenal ulcers in men and maybe even among the youngest women, support the trend indicated by Østensen et al. ${ }^{15}$ But the duodenal to gastric ulcer ratio depends to some extent on the diagnostic method applied. There is no duodenal preponderance among endoscopically diagnosed ulcers. However, as the previous studies 151819 are based on ulcers diagnosed by $x$ ray, a shift in the location is most likely, and is also in accordance with the results from the gastrointestinal study in Sørreisa, ${ }^{24}$ a rural municipality in the county of Troms.

Our almost equal gender specific risk of gastric ulcer was another somewhat surprising finding in this geographical area. Both Schanke ${ }^{19}$ and Østensen $e t$ al $^{15}$ found a male preponderance of peptic ulcer. In this study the highest difference between the sexes was observed among the youngest, aged 20 to 29 years. This may reflect a true cohort effect, or merely a change in gender related diagnostic intensity, as indicated in the Sørreisa study ${ }^{24}$ and the follow up study of Krag. ${ }^{27}$

None of the previously reported studies on peptic ulcer incidence has been censored for death and migration. As shown in the present study, censoring the population for death and migration is mandatory for a precise incidence estimate. Although not an earth shattering revelation, the difference between the uncensored and censored incidences of up to $20 \%$ should not be neglected.

The selection of patients for investigation still probably represents the major source of error. Both patient self selection and referral pattern will greatly influence the number of diagnosed cases. The ideal alternative-regular examinations of a population of the present size-is an insurmountable task. Thus we have to depend on incidences based on diagnostic routines, prescribed by our clinical practice in force at the time in question. This insight invites caution when comparing studies differing in time and geographical area.

In conclusion, our population based study has, in contrast to other recent studies, revealed an unchanged high incidence of gastric and duodenal ulcer in both sexes. Compared to previous studies from the area it indicates a change towards a preponderance of duodenal ulcers. The study has 
also demonstrated the impact of attendance rate, death and migration, and diagnostic methods on the incidences. Ignoring these potential biases may lead to conclusions on peptic ulcer trends that reflect artefacts rather than real changes in the epidemiology of peptic ulcer.

This study was done in cooperation with the National Health Survey Service, Oslo.

1 Langman MJS. Changing patterns in the epidemiology of peptic ulcer. Am 7 Gastroenterol 1973; 2: 219-26.

peptic ulcer. Am f Gastroenterol 1973, 2. 219-26. 1962; i: 115-9.

3 Sonnenberg A. Geographic and temporal variations in the occurrence of peptic ulcer disease. Scand $\mathcal{F}$ Gastroenterol 1985; 20 (suppl 110): 11-24.

4 Ihre BJE, Muller R. Gastric and duodenal ulcer. Acta Med Scand 1943; 116: 33-55.

5 Elashoff JD, Grossman MI. Trends in hospital admissions and death rates for peptic ulcer in the United States from 1970 to 1978 . Gastroenterology 1980; 78: 280-5.

6 Kurata JH, Elashoff JD, Haile BM, Honda GD. A reappraisal of time trends in ulcer disease: factors related to changes in ulcer hospitalization and mortality rates. $A m \mathcal{F}$ Public Health 1983; 73: 1066-72.

7 Walt R, Katschinski B, Logan R, Ashley J, Langman M. Rising frequency of ulcer perforation in elderly people in Rising frequency of ulcer perforation in elderly people in

the United Kingdom. Lancer 1986; i: 489-92.

Susser M. Period effects, generation effects and age effects in peptic ulcer mortality. F Chron Dis 1982; 35: 29-40.

9 Brown RC, Langman MJS, Lambert PM. Hospital admissions for peptic ulcer during 1958-72. BMF 1976; i: 35-7.

10 Coggon D, Lambert P, Langman MJS. 20 years of hospital admisions for peptic ulcer in England and Wales. Lancet 1981 ; i: $1302-4$.
11 Sonnenberg A. Changes in physician visits for gastric and duodenal ulcer in the United States during 1958-1984 as shown by National Disease and Threpeutic Index (NDTI) Dig Dis Sci 1987; 32: 1-7.

12 Kurata JH, Honds GD, Frankl H. The incidence of duodenal and gastric ulcers in a large health maintenance organization. Am $\mathcal{F}$ Public Health 1985; 75: 625-9.

13 Pulvertaft CN. Peptic ulcer in town and country. Br $₹$ Prev Soc Med 1959; 13: 131-8.

14 Litton A, Murdoch WR. Peptic ulcer in South-Wes Scotland. Gut 1963; 4: 360-6.

15 Østensen H, Gudmundsen TE, Bolz KD, Burhol PG Bonnevie $O$. The incidence of gastric ulcer and duodena ulcer in North Norway. A prospective epidemiological study. Scand $\mathcal{F}$ Gastroenterol 1985; 20: 189-92.

16 Bonnevie O. The incidence of duodenal ulcer in Copenhagen county. Scand 7 Gastoentorol 1975; 10: 385-93.

17 Bonnevie $O$. The incidence of gastric ulcer in Copenhagen county. Scand $\mathcal{F}$ Gastroenterol 1975; 10: 231-9.

18 Poppe E. Localization of peptic ulcus in a series of cases from Troms and Tromso hospital, Norway. Tids Norsk Lageforen 1945: 30: 1063-5.

19 Schanke K. The behaviour of gastric and duodenal ulcer. Acta Chir Scand 1946; 94 (suppl 115).

20 Sturdevant RAL. Epidemiology of peptic ulcer. Report of a conference. Am $\mathcal{f}$ Epidemiol $1976 ; 104$ : $9-14$.

conference. Am $\mathcal{f}$ Epidemiol 1976; 104: 9-14. Thelle DS, Arnesen E, Førde OH. The Tromsø heart study: 303: 1454-7.

22 SAS Institutes Inc. SUGI supplemental library user's guide. 5th ed. Cary, NC: SAS Institute Inc, 1986.

3 Fineberg HV, Pearlman LA. Surgical treatment of peptic ulcer in the United States. Lancet 1981; i: 1305-7.

24 Bernersen B, Johnsen R, Straume B, Burhol PG, Jenssen TG, Stakkevold PA. Towards a true prevalence of peptic ulcer: the Sørreisa gastrointestinal study. Gut 1990; 31: 989-92.

25 Dooley CP, Larson AW, Stace NH, et al. Double-contrast barium meal and upper gastrointestinal endoscopy. $A n n$ Intern Med 1984; 101: 538-45.

26 Schache DJ, Tovey FI, Masters A, Stebbing A, Rees M Changing pattern of duodenal ulcer? Lancet 1987; ii: 857 .

27 Krag E. Pseudo-ulcer and true peptic ulcer. A clinical radiographic and statistical follow-up study. Acta Med Scand 1965; 178: 713-28. 